MR. ANDRÉS CAMPOY (Orcid ID : 0000-0001-9412-3391)

Article type : Regular Paper

\title{
An in-depth study of the larval head skeleton and the external feeding structures related with the ingestion of food particles by the eristaline flower flies Eristalis tenax and Eristalinus aeneus
}

\author{
Andrés Campoy $^{1 *}$, Andrea Aracil ${ }^{1}$, Celeste Pérez-Bañón ${ }^{1}$ and Santos Rojo ${ }^{1}$ \\ ${ }^{1}$ Department of Environmental Sciences and Natural Resources, University of Alicante, PO \\ Box 99, E-03080 Alicante, Spain \\ *Corresponding author: andres.campoy@ua.es
}

Short title: Larval feeding mechanisms of two eristaline flies

Key words: artificial rearing, filter-feeding, head skeleton, hoverflies, larva, saprophagy, Diptera,

Syrphidae

Accepted: 11 May 2020

This article has been accepted for publication and undergone full peer review but has not been through the copyediting, typesetting, pagination and proofreading process, which may lead to differences between this version and the Version of Record. Please cite this article as doi: 10.1111/EEA.12974

This article is protected by copyright. All rights reserved 


\section{Abstract}

There is an important lack of knowledge regarding the mechanisms and morphology of the structures involved in the feeding process of the bee-mimicking eristaline flower fly species (Diptera: Syrphidae). In order to look more deeply into their larval feeding biology, a morphological study of the head skeleton and the external feeding structures of the three larval instars of Eristalis tenax (L.) and Eristalinus aeneus (Scopoli), important pollinators and bioindicators of water quality, was carried out, using scanning electron microscopy (SEM) and confocal laser scanning microscopy (CLSM). Additionally, an analysis of the ingested particle size was conducted, using various pollen grains and fungal spores. The main differences, found between the third instar larvae of both species, consisted of the more restrictive mandibular lobes of $E$. tenax, which prevent the ingestion of bigger particles, and a wider filtering area in the cibarium of $E$. aeneus, which increases the number of particles that can be retained and ingested. Eristalinus aeneus is able to ingest bigger particles ( $80-100 \mu \mathrm{m})$ than E. tenax $(70-80 \mu \mathrm{m})$. These results suggests that the structures involved in the feeding process of E. aeneus are less restrictive, thus increasing its survival chances when, under artificial rearing conditions, the same medium is used for both species. This study may contribute to the improvement of artificial rearing for future studies on pollination and decomposition.

\section{Abbreviated abstract}

Eristalis tenax (L.) and Eristalinus aeneus (Scopoli) (Diptera: Syrphidae) are important pollinators and bio-indicators of water quality. A morphological study of the head skeleton and the external feeding structures of their larval instars was performed, as well as an analysis of the size of ingested particles. Morphological differences were most pronounced among third instar larvae, and E. aeneus was able to ingest bigger particles. This study may contribute to improved artificial rearing conditions.

\section{Graphical abstract}

Graphical abstract.tif 


\section{Introduction}

The eristaline syrphid species (Diptera: Eristalinae, Eristalini) are well known for their efficiency as pollinators (Larson et al., 2001; Sajjad et al., 2008; Ssymank et al., 2008). Many studies show their importance as pollinators of crops of Apicaceae, Rosaceae, Solanaceae, Asteraceae, and Brassicaceae (Jarlan et al., 1997; Goubara \& Takasaki, 2003; Jauker \& Wolters, 2008; Willmer, 2011; Jauker et al., 2012). Moreover, eristalines can improve seed production inside isolation cages and greenhouses under controlled conditions (Wiering, 1964; Free, 1993). Their use as pollinators has led to the development and improvement of artificial rearing protocols for certain key species, such as Eristalis tenax (L.), Eristalis cerealis Fabricius, and Eristalinus aeneus (Scopoli), which are mainly based on animal excrement, rotten plants, or fermented cereals (AbouEl-Ela et al., 1978; Heal, 1979; Kobayashi, 1972, 1979; Rosso et al., 1994; Gladis, 1994a, 1994b, 1997; Nicholas et al., 2018). However, many details about their larval feeding biology remain unknown, which hinders industrial mass production. Specifically, one of the main bottlenecks is high mortality during larval development in artificial rearing conditions, being $68.75 \%$ in E. tenax and $62.95 \%$ in E. aeneus. Apart of the better survival rate demonstrated by E. aeneus, this species presents better perspectives to be artificially reared, displaying a higher longevity, maturation rate and fecundity than E. tenax (Campoy et al., 2020).

The life cycles of E. aeneus and E. tenax last ca. 2 and 1.5 months, respectively (Campoy et al., 2020). For both species, the larval stage goes through three instars during its development, each of them separated by a moulting process. The larvae are commonly known as 'rat-tailed maggots', due to their long posterior respiratory spiracle. They are aquatic and saprophagous, and frequently associated with liquid or semi-solid environments enriched with organic matter (Rotheray, 1993; Speight, 2020). As microphages, they feed on microorganisms (mainly bacteria and yeasts) and detritus by filtering the water (Mahmoud et al., 1999; Rotheray, 2019). This trophic feature makes these species suitable for bio-indication of the quality of aquatic environments and nutrient cycling in those bodies of water (Dziock et al., 2006; Burgio \& Sommaggio, 2007; Thompson et al., 2010).

The main structure involved in the water filtration process is the cephaloskeleton or head skeleton (Rotheray, 2019). This structure is the only sclerotised part of the so-called pseudocephalon, the reduced head of the cyclorrhaphous larvae (Ferrar, 1987; Courtney et al., 2000). Its morphology shares some similarities among species, showing high adaptation to the 
larval feeding habit and source of food (Roberts, 1970; Rotheray, 2016). Many studies have focused on the head skeleton over the years (Keilin, 1915; Hartley, 1963; Ferrar, 1987; Courtney et al., 2000), as it is an essential part in the morphological descriptions of cyclorrhaphous larvae. The importance of this structure resides in its taxonomical interest, showing several differences among species, and also in the amount of biological information that it provides in relation to larval feeding habits and habitat (Dowding, 1967; Roberts, 1970). It should be pointed out that this structure and its components have been given several names, most of them brought together by Courtney et al. (2000).

The external morphology involved in the feeding process of these microphages is made up of cephalic and thoracic structures. The feeding channel starts at the pseudocephalon, on both sides of the papillae bearing the antennomaxillary organs, which direct the stream of liquid food into the preoral cavity (Rotheray \& Gilbert, 1999). This cavity is formed of four lips: the dorsal and ventral lips belong to the pseudocephalon region, whereas the lateral lips are prothoracic structures (Hartley, 1963). These four lips, especially the lateral ones, act as a first coarse filter, stopping big particles from entering the mouth with the various types of setae coating them. The rest of the water and discarded particles are expelled down the channel between the mesothoracic prolegs (Rotheray, 2019).

The mandibular complex, composed of the mandibles, mandibular apodemes, and mandibular lobes, has lost its food-gathering function, unlike in the phytophagous and predatory syrphid species, as filter-feeding larvae collect liquid food with a suction pump (Rotheray \& Lyszkowski, 2015). The mandibular lobes act as a second filter by using the internal ridges and bristles to discard unsuitably big particles. The water is drawn into the atrium and the upper cibarial chamber by the pumping action of the atrial and cibarial muscles, which lift the epipharynx. When the cibarial roof comes down, the water is forced through the cibarial filaments, which constitute the third filter, retaining the food particles. The atrial valve, located between the atrium and the upper chamber of the cibarium, prevents the food particles from being expelled when the epipharynx is lowered. The filtered water is then forced out from the lower cibarial chamber, and the whole process is repeated until there are enough food particles (mainly microorganisms and suspended debris) attached to the cibarial filaments. At this point, the pharyngeal valve is opened, and the retained food is washed into the pharynx towards the foregut (Hartley, 1963; Roberts, 1970; Rotheray, 2019).

The main objective of this study is to fill the gaps of knowledge of the feeding mechanisms 
of larvae of two key eristaline flower fly species, E. aeneus and E. tenax. The following objectives were set: 1) to describe comparatively the micromorphology of the surface of the preoral cavity and head skeleton throughout the three larval instars, and 2) to determine the range of particle sizes that larvae are able to ingest by filtering. This information could contribute to the improvement of artificial rearing.

\section{Materials and methods}

\section{Sample collection}

Wild adults of E. aeneus and E. tenax were sampled in the surroundings of an effluent pond located on a pig farm in Fortuna, Murcia (Spain) to establish an initial colony in the facilities at the University of Alicante. Larvae obtained from these adults were used to conduct the present study. Larvae were reared in plastic containers $(15 \times 23 \times 10.5 \mathrm{~cm})$ with soaked oat grains (Avena sativa L.), based on the methodology described by Gladis (1993). Larval instars were distinguished by age and number of moults after egg hatching. First instar larvae were collected from the medium 1-2 days after egg hatching, before the appearance of the first moult; 2 nd instar larvae were collected after 4-6 days, after shedding the first moult; and 3rd instar larvae were collected after 15 days, when the second moult had been shed.

\section{Description of the micromorphology of the preoral cavity surface}

Following the methodology of Pérez-Bañón et al. (2013), the larvae were immersed in cold water to extend them, and heated slowly for ca. 4 min to kill them. The larvae were then preserved in $70 \%$ ethyl alcohol. The micromorphology was studied using a cryo-scanning electron microscopy technique (cryo-SEM), in which the material is frozen so quickly that vulnerable biological structures are well preserved. The larvae were fixed on a holder with a layer of O.C.T. compound (Tissue-Tek O.C.T. Compound, Sakura Finetek, Alphen aan den Rijn, The Netherlands), and frozen rapidly in liquid nitrogen for $2 \mathrm{~min}$. Afterwards, the specimen holder was transferred into a system for cryo-SEM (Oxford CT1500, Oxford Instruments, Abingdon, United Kingdom). The specimens were freeze-etched and maintained under vacuum conditions, increasing the temperature from $-150{ }^{\circ} \mathrm{C}$ to $-90^{\circ} \mathrm{C}$ for ca. 2 min to eliminate contamination by frost. After that, a thin layer of gold was 'sputtered' onto the material for $5 \mathrm{~min}$. Finally, the samples were transferred into the cold stage of the SEM (S3000N; Hitachi, Tokyo, Japan), kept at ca. $-150{ }^{\circ} \mathrm{C}$, and secondary electron images were taken at an accelerating voltage of $10 \mathrm{kV}$. Five larvae of each 
species and instar were used for morphological analysis of the preoral cavity surface. These studies were conducted at the technical services facilities at the Polytechnic University of Valencia (UPV, Spain).

\section{Description of head skeleton}

To study the head skeleton, two techniques were used. Firstly, a morphological analysis was conducted using SEM. Secondly, a preliminary study of the functional morphology of the structure was performed using confocal laser scanning microscopy (CLSM) on the first and second instar larvae. The descriptions follow the terminology established by Courtney et al. (2000), Rotheray and Gilbert (2008) and Rotheray (2019).

For SEM analysis, the larvae were killed in boiling water and preserved in $70 \%$ ethyl alcohol. The head skeleton was extracted by dissecting the larvae using a stereomicroscope (Leica M205C; Leica Microsystems, Amsterdam, The Netherlands). The dissection process consisted of separating the thorax from the abdominal segment. Afterwards, the thorax was cut along its dorsal midline section and all the muscles were removed. Once the head skeleton was visible, it was extracted by cutting the joint between the mandibular lobes and the external cuticle. The head skeletons were cleaned and photographed to measure the general structure using a camera (Leica DFC450; Leica Microsystems) adapted to the stereomicroscope (Leica M205C; Leica Microsystems). Later, the membrane covering the cibarial chamber (cibarium) was eliminated and the mandibular lobes were separated from the whole structure to observe the inner morphology using SEM.

The samples were mounted onto aluminium stubs using double-sided adhesive carbon tape and coated with a $10 \mathrm{~nm}$ layer of gold using a SDC004 model (Oerlikon Balzers, Balzers, Liechtenstein) diode sputter-coating unit. Afterwards, the samples were examined at $20 \mathrm{kV}$ in a SEM system (S3000N; Hitachi). These studies were conducted at the technical research services located at the University of Alicante. On the images obtained with SEM, the filtering structures and the distances between them were measured using the free computer software IMAGEJ v1.51 (https://imagej.nih.gov/ij/). Twenty-five specimens of each instar and species were used, however, not all structures were of high enough quality to be photographed and measured.

For CLSM analysis, the clearing protocol proposed by Smolla et al. (2014) was followed. First instar larvae were fixed with $4 \%$ formaldehyde (PBS) for $1.5 \mathrm{~h}$. A small incision was made to allow the fixative to enter all tissues. The larvae were washed three times with PBT (PBS with 
$0.3 \%$ of Triton) and overnighted in $15 \% \mathrm{H}_{2} \mathrm{O}_{2}$ solution to remove pigmentation. After this period, the larvae were washed with PBT three times and dehydrated using a graded ethanol series (50-7090-95-100\%). Dehydrated larval tissues were cleared in methyl salicylate. Chemicals were obtained from Sigma-Aldrich, St. Louis, MO, USA. The samples were mounted on microscope slides facing up using modelling clay spacers and covered with cover slides. Pictures were taken on a Zeiss LSM-510 CLSM (Zeiss, Oberkochen, Germany) with $488 \mathrm{~nm}$ emission light (argon laser) using a $20 \times$ dry objective and 0.8 zoom. The samples were scanned from top to bottom in sections. For the second instar, previous dissection of the larvae was required to facilitate the fixation of the tissue. The larvae were dissected following the description above, that is, the thorax was separated from the abdominal segment and cut along its dorsal midline section. After that, all of the muscles and fat tissue surrounding the skeleton were removed. Three larvae of each instar and species were used for the morphological analysis of the head skeleton using CLSM.

\section{Analysis of ingested particle size range}

The methodology of this experiment was adapted from Dowding (1967). Larvae were deprived of food for $3 \mathrm{~h}$. After this period, starved larvae were fed with particles (pollen grains and fungal spores) of selected size suspended in water (Table 1). A bibliographic research was performed to identify plant and fungus species which have pollen grains and fungal spores with known sizes, and were available in the area of study, to obtain enough material. These particles were obtained directly from the field and their size was verified using a micrometric eyepiece coupled to the microscope (Leica CME; Leica Microsystems). This procedure was supervised by the curator of the $\mathrm{ABH}$ herbarium.

Fifteen starved larvae from each instar and species were placed in groups of five in Petri dishes (9 cm diameter) with water and particles in suspension $(60 \mathrm{ml}, 50 \%$ concentration of particles). Each particle type was tested separately. The larvae were left in the Petri dishes for $5 \mathrm{~h}$, moving them to resuspend the particles periodically. Once this time had elapsed, the larvae were killed with boiling water and preserved in $70 \%$ ethyl alcohol.

To analyse the presence of particles in the gut, the surface of the larvae was cleaned with water and $70 \%$ ethyl alcohol and the digestive tract was extracted. The contents of the midgut were spread on a microscopic slide and the presence or absence of particles was verified using a microscope (Leica CME; Leica Microsystems). An analysis of the frequency of intake of particles was performed, thus establishing the size range of particles ingested by the larvae of each instar 
and species.

\section{Results}

The general structure and morphology of the preoral cavity surface and head skeleton are similar in both species and in the three larval instars. However, there are differences with regards to size, ornamentation, degree of sclerotisation, and shape of sclerites, among others.

\section{Eristalinus aeneus}

\section{Micromorphology of the preoral cavity surface}

The preoral cavity is formed of four lips: two lateral, one ventral (also known as the labial lobe), and one dorsal lip. In third instar larvae, the lateral lips are oval-shaped and well developed, and a groove on their lower third divides them into two lobes (upper and lower). The inner surface of the upper lobe and the whole surface of the lower lobe are densely covered in long setae; on the outer surface of the upper lobe, setae are also present, but scarce; on the top of the upper lobe there is a patch of ramified setae. The dorsal lip is situated in the upper part of the preoral cavity, below the antennomaxillary organs; it is characterized by a tuft of setae and a pair of sensilla (Figure 1A). The ventral lip is sunk, located under the preoral cavity, and formed of two lobes (outer and inner). The outer lobe has a pair of sensilla and is ornamented with papillae that look like small combs with sharp, short and thick teeth; these combs get gradually bigger towards the inner lobe (Figure 1D). These four lips, especially the two lateral lips, constitute the first filter, which prevents the blockage of the preoral cavity by stopping big particles. The feeding channel starts at both sides of the papillae bearing the antennomaxillary organs, reaches the preoral cavity surrounded by the four lips, and continues between the mesothoracic prolegs out of the body.

In second instar larvae, the ornamentation of the external lips is similar to that described above for third instar larvae, except for the lateral lips, of which both lobes (inner and outer) are fully coated in long setae (Figure 1B).

Regarding first instar larvae, the lateral lips are less developed than in the other instars, and are fully covered in very thin setae. They already present the groove that separates them into two lobes. The ventral lip displays a different ornamentation: the comb structures are reduced to papillae that end in 1-3 tips, and the pair of sensilla on the outer lobe are already present. The dorsal lip has the same structure as in the third instar larvae, but the tuft of setae is less developed. The joining point of the two mandibular lobes is thickened, giving the misleading impression, 
together with the artificial evagination of the mandibular lobes, that the oral cavity is divided into two cavities (Figure 1C).

\section{Structure and morphology of head skeleton}

The head skeleton is divided into three main parts: anteriorly the mandibular complex, followed by the intermediate sclerite, and, most posteriorly, the basal sclerite.

Starting from the posterior part, for third instar larvae, the basal sclerite is two times longer (2.31 $\mathrm{mm}$ ) than it is high $(0.92 \mathrm{~mm})$, the distance between the two dorsal cornua is $0.77 \mathrm{~mm}$, and the width of the cibarial chamber is $0.69 \mathrm{~mm}$ (Table 2). The dorsal cornua are rounded at the apex, representing one-fifth of the total length of the basal sclerite, and are joined to each other by the dorsal bridge, a sclerotised structure located at the anterior part of the basal sclerite. Beneath the dorsal bridge is the optic depression, a sunken structure surrounded by a sclerotised area in which sensory receptors are found. The labrum is present as a curved membrane that starts in the optic depression and reaches up the mandibular lobes. The vertical plate comes down from the dorsal cornua and extends into the ventral arms, which run along one-fifth of the cibarial chamber. The cibarium is the largest part of the ventral cornu (Figure 2A). It is a boat-shaped structure covered by a lightly sclerotised cuticle, the epipharynx. On the floor of this chamber, the hypopharynx, there are nine evaginations or ridges which run along the whole length of the chamber, and are 74 $\mu \mathrm{m}$ apart. The apex of the ridges splits into two rows of filaments, forming Y-shaped structures, except for the ridges at the edges, on which one row of filaments is fused to the wall of the chamber. The number of filaments per mm of ridge is ca. 1250 . The filaments in each row are attached to each other by a widening and a small depression present at their apex. Also, they are in contact with the filaments of the adjacent ridges (Figure 3C). The filaments are ca. $45 \mu \mathrm{m}$ long (Table 3).

The intermediate sclerite is present just behind the mandibular lobes, forming the atrium. This cavity is bounded dorsally by the epipharyngeal plate, which is a very thin, sclerotised structure that projects from the basal sclerite and reaches more than half the length of the mandibles (Figure 2A). Laterally and ventrally, the atrium is flanked by the labium. The labium is formed of labial rods which consist of two thin and sclerotised bars that get wider at the apex and are joined together ventrally by the labial bridge. They bound the atrium laterally and connect the basal sclerite to the mandibles. The labium is also formed of the labial sclerites, which are thin and triangular in shape, and the labial plate, which is a flattened structure fused to the labial bridge. 
Both structures are located at the ventral part of the atrium (Figure 2B).

Finally, the mandibular complex is formed of the mandibles, the mandibular apodemes, and the mandibular lobes. The mandibles (located dorsally) and the mandibular apodemes are fused, forming a C-shaped sclerotised structure that provides support for the mandibular lobes, which are membranous. The mandibular lobes are broad and rounded structures that are flattened at the anterior part and dorsally joined (Figures 2A and B). The inner surface of the lobes is covered by evaginations that form ca. 10 ridges on each lobe, $33.71 \mu \mathrm{m}$ apart. These ridges are comb-shaped and have bristles on the external margin of their lateral projections that reach the inner margin of the adjacent ridge. The number of bristles on each ridge varies between 22-25, and the gap between them is ca. $6 \mu \mathrm{m}$ (Figures 3A and B). Each bristle is $12.78 \mu \mathrm{m}$ long (Table 4).

In the second instar, the structure and proportions of the head skeleton are similar to the third instar (0.39 mm high, $1.07 \mathrm{~mm}$ long) but with a lower degree of sclerotisation (Table 2). Despite the differences in size, the number of ridges in the mandibular lobes remains constant. The number of ridges in the cibarial chamber is reduced to seven in the second instar, instead of nine in the third instar.

In the first instar, the head skeleton is almost five times longer $(0.49 \mathrm{~mm})$ than it is high $(0.13 \mathrm{~mm})$ (Table 2$)$. The degree of sclerotisation is very low, and the dorsal cornua and the mandibles are the most sclerotised parts. In this instar, the labrum is well sclerotised and developed, joining the two dorsal cornua, and it projects forward, finishing in a sharp apex. The epipharyngeal plate is hardly developed, being a slightly sclerotised membrane beneath the labrum (Figure 2C). The labial rods are very thin, and the labial bridge is present but hardly sclerotised. Labial sclerites and the labial plate are not noticeable in this instar (Figure 2D). The number of ridges inside the mandibular lobes is the same as in the later instars, but bristles are not present. The cibarial chamber only has two ridges, each having one row of filaments projecting towards the inner part of the cibarium, covering the whole surface.

\section{Analysis of ingested particle size range}

Pollen grains of Lavatera cretica L. $(100 \mu \mathrm{m})$ were not present in the digestive tract of third instar larvae ( $0 \%$ of larvae ingested these particles). These grains were too big, were retained by the external filter and the mandibular lobes, and thus did not enter the gut of the larvae. Pollen grains of 50-80 $\mu \mathrm{m}$ were found in $67-80 \%$ of fed larvae, and particles of $6-50 \mu \mathrm{m}$ were found in $100 \%$ of fed larvae, indicating that the maximum size of particles that third instar E. aeneus larvae can filter 
is $80-100 \mu \mathrm{m}$ (Figure 4).

Second instar larvae fed with Convolvulus althaeoides L. $(65-70 \mu \mathrm{m})$ showed no grains of pollen in their digestive tract. However, $87-100 \%$ of larvae fed with smaller sized particles (6-50 $\mu \mathrm{m})$ had pollen grains inside their digestive tract. Therefore, the maximum particle filtering size for second instar larvae instar is 50-65 $\mu \mathrm{m}$ (Figure 4).

First instar larvae were only able to ingest spores of Inocybe spp. (Fr.) Fr. $(12 \times 7 \mu \mathrm{m})$ and Agrocybe aegerita (V. Brig.) Sing. $(12 \times 6 \mu \mathrm{m})$, establishing a maximum ingestion size range of 6$12 \mu \mathrm{m}$ (Figure 4).

\section{Eristalis tenax}

Micromorphology of the preoral cavity surface

As for E. aeneus, the preoral cavity of third instar E. tenax larvae is surrounded by four lips, which act as a first filter. The lateral lips are oval in shape, are well developed, and present a groove in the basal third which separates them into two lobes (upper and lower). Both lobes are fully covered in setae, which are shorter in the upper area and generally get longer on the inner side of the lower lobe (Figure 5A). The dorsal lip has a tuft of setae and a pair of sensilla. The ventral lip is sunk and consists of two lobes (outer and inner). The ornamentation on the outer lobe is almost absent except for a pair of sensilla, whereas the inner lobe is ornamented with papillae ending in 13 tips (Figure 5D). The feeding channel, which begins in the upper part of the pseudocephalon, is delimited by the papillae with the antennomaxillary organs and flows into the preoral cavity. The expelled water leaves the body between the mesothoracic prolegs.

In the second instar, the ornamentation of the external lips is similar to the one described for the third instar, except for the lateral lips. Here, the setae appear to be thinner, covering the whole surface of the lobes, in contrast with the third instar, in which the setae are more scattered (Figure 5B).

In the first instar, the lateral lips are well developed and coated in longer and thinner setae, but they are not yet divided into two lobes. The two lobes of the ventral lip are clearly visible and covered in not well-defined papillae with 1-3 tips, and at the end of the ventral lip appear a pair of sensilla. The dorsal lip presents a pair of sensilla and the tuft of setae is not yet well defined. The joining point between the mandibular lobes is enlarged, giving the false impression, together with the artificial evagination of the prothorax, that the oral cavity is divided into two parts (Figure 5C). 


\section{Structure and morphology of head skeleton}

The basal sclerite of the third instar is two times longer $(2.33 \mathrm{~mm})$ than it is high $(1.12 \mathrm{~mm})$, the two dorsal cornua are separated by $0.79 \mathrm{~mm}$, and the width of the cibarial chamber is $0.52 \mathrm{~mm}$ (Table 2). The dorsal cornua are heavily sclerotised, with the apex elongated backwards, and cover one-fourth of the ventral cornu; the dorsal cornua are joined together at the anterior part by the dorsal bridge. The optic depression appears below this bridge, from which the labrum extends, reaching the mandibular lobes. From the dorsal cornua, the vertical plate is prolonged ventrally up to the ventral cornu, in which the ventral arms reach around one third of the cibarial chamber (Figure 6A). The cibarium presents nine ridges ventrally, which split into two rows of thin filaments, Y-shaped in cross section, except for the lateral ridges with one of the rows fused to the wall of the chamber (Figure 7C). The length of the ridges is $1500 \mu \mathrm{m}$, and the number of filaments per millimetre of ridge is 1397 , so there are ca. 2000 filaments per ridge. The filaments get wider at the apex, like a spoon, and they have a depression in the centre. This structure aids the adhesion of the filaments in the same row. The length of the filaments is $38.34 \mu \mathrm{m}$ (Table 3 ).

On the intermediate sclerite, the labial rods (which project from the basal sclerite towards the mandibles) are long and thin, becoming wider at the apex, where they connect to each other via the labial bridge. The epipharyngeal plate is thickened, projecting from the basal sclerite, and reaching the posterior edge of the mandibles. The labial sclerites are thin and rounded in shape, and form the floor of the atrium together with the labial plate (Figures $6 \mathrm{~A}$ and $\mathrm{B}$ ).

The mandibular lobes are ovoid structures that are supported by the C-shaped structures formed by the mandibles and mandibular apodemes, which are well sclerotised (Figure 6A). Both lobes are joined dorsally. The inner walls of the mandibular lobes present ridges that cover the whole length of the lobe; there are ca. 20 ridges per lobe, and the separation between them is 13.73 $\mu \mathrm{m}$ (Figure 7A). At the posterior end of the lobe, the ridges separate from the wall and arch themselves, forming a structure like an inverted funnel (Figure 7B). These ridges are covered in bristles, which are separated by $2.84 \mu \mathrm{m}$. The bristles are $6.92 \mu \mathrm{m}$ long. There are ca. 2.54 bristles per $10 \mu \mathrm{m}$ of ridge (Table 4 ).

In the second instar, the head skeleton remains constant with respect to the third instar; proportions are similar $(0.51 \mathrm{~mm}$ high, $1.16 \mathrm{~mm}$ long), but the head skeleton is less sclerotised (Table 2). The number of ridges on the mandibular lobe is the same, but the number of ridges in the cibarial chamber falls to seven (Figure 8A).

Regarding the first instar, the head skeleton is almost three times longer $(0.46 \mathrm{~mm})$ than it 
is high $(0.16 \mathrm{~mm})$ (Table 2$)$, and is more or less sclerotised in various parts. In this instar, the labrum is sclerotised, joining the two dorsal cornua and projecting towards the mandibular lobes. It becomes sharp at the apex. The epipharyngeal plate is already sclerotised, and under the labrum (Figure 6C). The labial rods are very thin and extend to the mandibular lobes, and the labial bridge is starting to appear at the base of each rod, but is not fused at the central part of the structure yet. The labial plate and the labial sclerites are not noticeable. The mandibles are sclerotised (Figure 6D). The mandibular lobes present the same number of ridges as the following instars, but they are not well sclerotised and the bristles are absent (Figure 8B; Supplementary material). In the cibarial chamber there are only two ridges, which are situated next to the walls of the chamber. These ridges have one row of filaments fused to the wall and the other projecting towards the inner part of the chamber (Figure 8C, Supplementary material).

\section{Analysis of ingested particle size range}

Third instar larvae fed with L. cretica $(100 \mu \mathrm{m})$ and Pelargonium zonale (L.) L'Hér. $(80 \mu \mathrm{m})$ pollen did not contain pollen grains in their digestive tract. However, smaller particles $(6-70 \mu \mathrm{m})$ were observed in the digestive tracts of $87-100 \%$ of larvae. These data suggest that the maximum particle size that third instar E. tenax larvae can filter is 70-80 $\mu \mathrm{m}$ (Figure 9).

No second instar larvae showed pollen grains of $C$. althaeoides $(65-70 \mu \mathrm{m})$ or Pinus halepensis Mill. $(50 \times 80 \mu \mathrm{m})$ in their digestive tracts, whereas $87 \%$ of fed larvae contained pollen grains of Acacia dealbata Link. (50 $\mu \mathrm{m})$, and all larvae fed with smaller particles $(6-40 \mu \mathrm{m})$ contained these particles in their digestive tracts. Thus, the maximum size of particles that second instar larvae can filter is 50-65 $\mu \mathrm{m}$ (Figure 9).

First instar larvae were only able to ingest spores of Inocybe spp. $(12 \times 7 \mu \mathrm{m})$ and $A$. aegerita $(12 \times 6 \mu \mathrm{m})$, which were present inside the midguts and hindguts of all larvae. The maximum size of ingested particles was found to be 6-12 $\mu \mathrm{m}$ (Figure 9).

\section{Discussion}

Comparison between the feeding mechanisms of $\mathrm{E}$. tenax and $\mathrm{E}$. aeneus

Despite the ecological and applied importance given to eristaline saprophagous larvae, the head skeleton of only a few species has been accurately described. For instance, much more information is still required for the synanthropic and cosmopolitan dronefly, i.e., E. tenax, which has been proposed as a model for aquatic microphagous syrphid larvae (Wilkinson, 1901; Krüger, 1926; 
Hartley, 1963). The eristaline rat-tailed species whose head skeletons have been described include Myathropa florea (L.), Eristalinus taeniops (Wiedemann), and several species of the genus Mallota (e.g., Roberts, 1970; Maier, 1978; Mahmoud et al., 1999).

In relation to the preoral cavity ornamentation surrounding the oral opening, the main differences between E. tenax and E. aeneus concerned the lateral lips. Eristalinus aeneus presents ramified setae on the outer surface of the upper lobe, which are not present in E. tenax. The head skeletons of E. tenax and E. aeneus share many general traits, due to the similar feeding habits and habitat conditions of both species. However, besides revealing differences in the degree of sclerotisation and size, detailed morphological analysis could explain why the two species respond differently to the artificial rearing processes (Campoy et al., 2020).

The greatest morphological differences between the two species were found in the mandibular lobes. Firstly, the overall morphology and degree of sclerotisation differed; the mandibular lobes are ovoid in shape and well sclerotised in E. tenax, but rounded and membranous in E. aeneus, in which just the mouth opening is sclerotised. The mouth opening is much wider in E. aeneus, whereas it is narrow and extended in E. tenax. Secondly, inside the mandibular lobes are a variable number of ridges, and accounting for intraspecific variation, the average number of ridges per lobe is almost twice as high in E. tenax (19.3) than in E. aeneus (10.2). As a consequence, the ridges are far more separated in E. aeneus $(33.71 \mu \mathrm{m}$ distance between ridges) than in E. tenax $(13.73 \mu \mathrm{m})$. The C-shaped structure of the mandibles is also present in M. florea and E. taeniops. Both species possess mandibular lobes, described as 'hemispherical cuticular shells', which indicates that they are not strongly sclerotised, but membranous like in E. aeneus. Roberts (1970) did not mention the number of ridges present in the mandibular lobes of $M$. florea, but he drew 23 ridges in a diagram, so they are approximately as numerous as in E. tenax. For E. taeniops, Mahmoud et al. (1999) mentioned 10 ridges per lobe, thus similar to E. aeneus. These ridges break away from the lobe's wall at its posterior end in $M$. florea and E. tenax, but they do not in the case of E. taeniops and E. aeneus, where the ridges are continuously attached to the lobes.

As mentioned above, the ridges present on the mandibular lobe are covered in bristles, which are perpendicular to the ridges, thus increasing the filtering area. The number of bristles per ridge and their shape also vary between species. In E. tenax, the bristles are straight, like fingers, and there are 2.54 bristles in $10 \mu \mathrm{m}$, each one separated by $2.84 \mu \mathrm{m}$. In E. aeneus, these bristles have a spoon-like shape with a wider apex, and there are 1.57 bristles in $10 \mu \mathrm{m}$, each one 
separated by $5.85 \mu \mathrm{m}$. Bristles are also present in $M$. florea and E. taeniops, although the only information available is a separation of $4 \mu \mathrm{m}$ between bristles in M. florea (Roberts, 1970). Altogether, this suggests that the second filter, i.e., the mandibular lobes, is less restrictive in $E$. aeneus, thus enabling this species to ingest more and bigger particles than E. tenax.

The basal sclerite is slightly higher, longer, and more sclerotised in E. tenax, also presenting longer dorsal cornua. Following the description of Rotheray (2019) and Roberts (1970, 1971), some morphological features, such as elongated cornua and a greater degree of sclerotisation of the basal sclerite, could be related to a shorter and stronger cibarial musculature, in particular with reference to the cibarial dilator muscles. This would produce a faster and stronger pumping action, increasing the volume of food intake per unit of time. Hypothetically, it suggests that the head skeleton of E. tenax, being more restrictive than E. aeneus, requires a stronger pumping system to obtain a similar amount of nourishment, whereas E. aeneus, presenting a less restrictive feeding system, would obtain the same amount of nutrients with a lower energy consumption. Dorsal cornua (= clypeal sclerites; Roberts, 1970) are small sclerites in M. florea, although no other information is provided, and therefore it is not possible to compare them with those in E. tenax and E. aeneus. In the case of E. taeniops, Mahmoud et al. (1999) did not describe them.

In the cibarial chamber of both species, nine ridges were present in the third instar, covered in filaments attached to each other, acting as the third filter. These ridges are more separated in $E$. aeneus $(74.39 \mu \mathrm{m})$ than in E. tenax $(51.06 \mu \mathrm{m})$. Additionally, the filaments in E. tenax are more abundant, shorter, and wider than those found in E. aeneus. Hartley (1963) mentioned that he found 2000 filaments per mm in E. tenax, although in this study, 1396 filaments per mm were observed on average, ranging between 1102 and 1908, which suggests that the number of filaments can vary within species. This last filter could be considered the most important, sieving and concentrating the food particles that will be ingested, mainly microorganisms and small detritus particles (Figures 10A,B). These observations suggest that if E. aeneus ingests more and bigger particles due to its less restrictive mandibular lobes, a wider filtering area would be needed. It was observed that the cibarium is wider, as well as the separation between ridges and bristles, preventing the filter from becoming obstructed and letting the water flow.

These conclusions are supported by the results from the analysis of ingested particle size range, in which the third instar larvae of E. aeneus (80-100 $\mu \mathrm{m}$ max.) were able to ingest a bigger range of particle sizes than E. tenax (70-80 $\mu \mathrm{m}$ max.). These results differ from the opinion of 
Hartley (1963) and Roberts (1970), who claimed that the maximum particle size that E. tenax and M. florea could ingest was $4 \mu \mathrm{m}$ on the basis of the maximum gap between the mandibular lobe's bristles. However, mandibular lobes are not rigid and immobile structures, but flexible, and expand and contract during the water suction process. This fact allows the ingestion of particles that are bigger than the distance between bristles, although most larger particles are indeed retained and rejected.

The cibarium seems to be a highly conserved structure among the saprophagous syrphid larvae, generally consisting of a boat-shaped structure with nine and seven ridges in the third and second instar, respectively (the first instar is not frequently studied) (Dowding, 1967; Roberts, 1970). Both M. florea and E. taeniops showed the same structure as E. aeneus and E. tenax, also displaying a Y-shaped cross-section. This structure is also present in other well-known dipteran species such as Calliphora vicina Robineau-Desvoidy (Dowding, 1967) and Drosophila melanogaster Meigen (Wipfler et al., 2013), having a similar morphology. The main differences are found in the distance between ridges, the number of filaments, and the distance between them, which are all factors responsible for giving these filters more or less particle-gathering capability in the different species.

It is important to highlight that the morphology of the feeding structures of E. aeneus and

E. tenax was studied from larvae reared using an artificial diet (soaked oat grains) instead of the medium where these species were observed (liquid pig slurries). Some studies have reported evidence of phenotypic variation in the anatomy of the mouthparts of herbivorous insect species when reared on media of different nature and consistency (Clissold, 2008; Ennis et al., 2015). However, in this case, the main food source consists of the microorganisms present in liquid sources, showing a similar consistency and toughness. Therefore, the phenotypic or developmental plasticity due to the variation of the rearing medium would be minimal. Nevertheless, this fact should be taken into account in future studies.

\section{Comparison between larval instars of $E$. tenax and $E$. aeneus}

During the larval development of both species, the most obvious differences between instars are found in their size and the degree of sclerotisation. The head skeleton of third instar larvae is twice as large as the second instar and five times longer and higher than the first instar in E. aeneus and E. tenax. Comparing the skeleton between third and second instars, the two are quite similar in appearance. This structure is completely formed in the second instar with just a lower degree of 
sclerotisation, mainly in the basal sclerite of both species, the labium in E. aeneus, and the mandibular lobes in E. tenax. Additionally, the number of cibarial ridges is reduced from nine in the third instar to seven in the second instar.

The main and most obvious differences are found when comparing the third and first instars. The mandibular lobes contain a similar number of ridges in the two instars. The exact number was not counted for the first instar, but these are very close to each other and lack the bristles. In the first instar, the ridges are probably the main filtrating structure in the mandibular lobe, as they are very close to each other. As they grow in size, the bristles appear to increase the filtering surface. The labrum is not fused to the basal sclerite in the first instar, and it projects forward. This structure presents a sharp apex, which acts as an egg cutter when hatching from the egg (Hartley, 1963). This sharp structure can even remain constant in the following instars in some predatory species of syrphids (Hartley, 1963; Roberts, 1970; Courtney et al., 2000; Rotheray \& Lyszkowski, 2015). The labium is not completely formed in the first instar, being fused but not well sclerotised in E. aeneus and more sclerotised but not yet completely fused in E. tenax. Finally, the cibarium only presents two ridges instead of nine. These two ridges, which are Yshaped in cross-section, have one row of filaments fused to the cibarial walls and the other row projecting to the inner channel, and are the only filter for concentrating the food particles that are ingested.

\section{Conclusions}

In this study, it was observed that the mandibular lobes allow the intake of more and bigger food particles in E. aeneus than in E. tenax, due to the lower number of ridges and bristles and the wider oral cavity. The more robust basal sclerite and longer cornua could point to a stronger pumping system in the case of E. tenax, which requires larger volumes of water to obtain the same amount of food as E. aeneus. The cibarium of E. aeneus presents a wider filtering area, thus increasing the amount of retained particles that can be ingested, and the separation between filaments is greater, to prevent the obstruction of the filter. Finally, the analysis of ingested particle size supports these statements, showing bigger particles in the digestive system of E. aeneus. It can be concluded that the feeding structures of E. tenax are more restrictive than in E. aeneus, thus reducing the number of suitable particles to feed on, and, consequently, the survival rate (Campoy et al., 2020). These features of the larval feeding mechanism need to be considered in order to develop suitable future artificial rearing media for the mass production of flower flies as effective 
pollinators and organic decomposers.

\section{Acknowledgments}

The project has been funded by the Spanish Ministry of Universities (MIU) in the frame of the FPU grant (FPU19-01985). Special thanks should be given to José Carlos Cristobal, curator of $\mathrm{ABH}$ herbarium (University of Alicante), for his help in the selection of the pollen grains and fungal spores used in the experiments. Also, we would like to thank Fernando Casares and his Control of organ growth and identity during development and evolution research team from CABD (CSIC-Pablo de Olavide University, Seville, Spain) for helping us with the techniques of confocal microscopy.

\section{References}

Abou-El-Ela R, Taher M \& Nazer I (1978) On the biology of Eristalis aeneus (Scopoli) in Saudi Arabia (Diptera: Syrphidae). Journal of the Faculty of Science Riyad University 9: 73-86. Burgio G \& Sommaggio D (2007) Syrphids as landscape bioindicators in Italian agroecosystems. Agriculture, Ecosystems and Environment 120: 416-422.

Campoy A, Sáez L, Pérez-Bañón C \& Rojo S (2020) Demography and population parameters of two species of eristaline flower flies (Diptera, Syrphidae, Eristalini). Journal of Applied Entomology 144: 133-143.

Clissold FJ (2008) The biomechanics of chewing and plant fracture: mechanisms and implications. Advances in Insect physiology 34: 317-372.

Courtney GW, Sinclair BJ \& Meier R (2000) Morphology and terminology of Diptera larvae. Contributions to a Manual of Palaearctic Diptera (with Special Reference to Flies of Economic Importance) (ed. by L Papp \& B Darvas), pp. 85-161. Science Herald, Budapest, Hungary.

Dowding VM (1967) The function and ecological significance of the pharyngeal ridges occurring in the larvae of some cyclorrhaphous Diptera. Parasitology 57: 371-388.

Dziock F, Henle K, Foeckler F, Follner K \& Scholz M (2006) Biological indicator systems in floodplains. International Review of Hydrobiology 91: 271-291.

Ennis DE, Mader BJ, Burnside K, Bruce E \& Despland E (2015) Is feeding behaviour on foliage affected by lab-rearing on artificial diet? Journal of Insect Behaviour 28: 147-156.

Ferrar P (1987) A Guide to the Breeding Habits and Immature Stages of Diptera Cyclorrhapha. 
Entomonograph 8 (ed. by L Lyneborg). EJ Brill, Leiden, The Netherlands.

Free JB (1993) Insect Pollination of Crops. Academic Press, London, UK.

Gladis T (1993) Laboratory rearing of some eristalines (Diptera, Syrphidae) and the possibility of their use in plant cultures. Verhandlungen der Westdeutscher Entomologentag, 139-152. Dusseldorf, Germany.

Gladis T (1994a) Rearing methods and beneficial likelihood for native insects as pollinators of outcrossing cultivated plant species. Schriftenreihe des Länderinstituts für Bienenkunde (ed. by C Hedtke), pp. 10-23. Länderinstitut für Bienenkunde, Hohen Neuendorf, Germany.

Gladis T (1994b) Establishment and utilization of a mass rearing of Eristalis tenax (Diptera, Syrphidae) in the Gatersleben gene-bank. Insecta 1: 287-294.

Gladis T (1997) Bees versus flies? Rearing methods and effectiveness of pollinators in crop germplasm regeneration. Acta Horticulturae 437: 235-238.

Goubara M \& Takasaki T (2003) Flower visitors of lettuce under field and enclosure conditions. Applied Entomology and Zoology 38: 571-581.

Hartley JC (1963) The cephalopharyngeal apparatus of syrphid larvae and its relationship to other Diptera. Proceedings of the Zoological Society of London 141: 261-280.

Heal J (1979) Colour patterns of Syrphidae: genetic variation in the dronefly Eristalis tenax. Heredity 42: 223-236.

Jarlan A, De Oliveira D \& Gingras J (1997) Effects on Eristalis tenax (Diptera: Syrphidae) pollination on characteristics of greenhouse sweet pepper fruits. Journal of Economic Entomology 90: 1650-1654.

Jauker F \& Wolters V (2008) Hover flies are efficient pollinators of oilseed rape. Oecologia 156: 819-23.

Jauker F, Bondarenko B, Becker HC \& Steffan-Dewenter I (2012) Pollination efficiency of wild bees and hoverflies provided to oilseed rape. Agricultural and Forest Entomology 14: 8187.

Keilin D (1915) Récherches sur les larves de Diptères Cyclorrhaphes. Bulletin Scientifique de la France et de la Belgique 49: 15-198.

Kobayashi M (1972) Problems in the utilisation of Eristalis cerealis as pollinator. Shokubutsu Boeki 26: 473-478.

Kobayashi M (1979) A study on multiplication and utilization of insects pollinating horticultural 
crops. Bulletin of the Iwate Horticultural Experiment Station Special Issue 1: 1-167.

Krüger F (1926) Biologie und Morphologie einiger Syrphidenlarven. Zeitschrift für Morphologie und Ökologie der Tiere 6: 83-149.

Larson BMH, Inouye DW \& Kevan PG (2001) Flies and flowers: taxonomic diversity of anthophiles and pollinators. Canadian Entomologist 133: 439-465.

Mahmoud M, Bahgat M, Zalat S \& Dewedar A (1999) Eristalinus larvae and the role of bacteria in their feeding. Zoology 11A: 417-433.

Maier CT (1978) The immature stages and biology of Mallota posticata (Fabricius) (Diptera: Syrphidae). Proceedings of the Entomological Society of Washington 80: 424-440.

Nicholas S, Thyselius M, Holden M \& Nordström K (2018) Rearing and long-term maintenance of Eristalis tenax hoverflies for research studies. Journal of Visualized Experiments 135: $1-6$.

Palazón-Lozano F (2001) Setas para Todos. Pirineo, Huesca, Spain.

Pérez-Bañón C, Hurtado P, García-Gras E \& Rojo S (2013) SEM studies on immature stages of the drone flies (Diptera: Syrphidae): Eristalis similis (Fallen, 1817) and Eristalis tenax (Linnaeus, 1758). Microscopy Research and Technique 76: 853-861.

Roberts MJ (1970) The structure of the mouthparts of syrphid larvae (Diptera) in relation to feeding habits. Acta Zoologica 51: 43-65.

Roberts MJ (1971) The structure of the mouthparts of some calypterate dipteran larvae in relation to their feeding habits. Acta Zoologica 52: 171-188.

Rosso H, Rao VR \& Gladis T (1994) Laborzucht von Eristalis tenax (Diptera: Syrphidae) zur kontrollierten Bestäubung von Kulturpflanzen [Laboratory rearing of Eristalis tenax (Diptera: Syrphidae) for controlled pollination of cultivated plants]. Mitteilungsblatt der Entomologen-Vereinigung Sachsen-Anhalt e.V. 2: 6-9.

Rotheray GE (1993) Colour guide to hoverfly larvae (Diptera, Syrphidae) in Britain and Europe. Whiteley, Sheffield, UK.

Rotheray GE (2016) Improving knowledge of the cyclorrhaphan larva (Diptera). Journal of Natural History 50: 35-36.

Rotheray GE (2019) Ecomorphology of Cyclorrhaphan Larvae (Diptera). Zoological Monographs 4 (ed. by H Feldhaar \& A Schmidt-Rhaesa). Springer Nature Switzerland, Cham, Switzerland.

Rotheray GE \& Gilbert F (1999) Phylogeny of Paleartic Syrphidae (Diptera): evidence from larval 
stages. Zoological Journal of the Linnean Society 127: 1-112.

Rotheray GE \& Gilbert F (2008) Phylogenic relationships and the larval head of the lower Cyclorrhapha (Diptera). Zoological Journal of the Linnean Society 153: 287-323.

Rotheray GE \& Lyszkowski RL (2015) Diverse mechanisms of feeding and movement in Cyclorrhaphan larvae (Diptera). Journal of Natural History 49: 2139-2211.

Sajjad A, Saeed S \& Masood A (2008) Pollinator community of onion (Allium cepa L.) and its role in crop reproductive success. Pakistan Journal of Zoology 40: 451-456.

Smolla M, Ruchty M, Nagel M \& Kleineidam CJ (2014) Clearing pigmented insect cuticle to investigate small insects' organs in situ using confocal laser-scanning microscopy (CLSM). Arthropod Structure and Development 43: 175-181.

Speight MCD (2020) Species accounts of European Syrphidae, 2020. Syrph the Net, the database of European Syrphidae (Diptera) (ed. by MCD Speight, E Castella, JP Sarthou \& C Vanappelghem), pp. 79-87. Syrph the Net Publications, Dublin, Ireland.

Ssymank A, Kearns CA, Pape T \& Thompson FC (2008) Pollinating flies (Diptera): a major contribution to plant diversity and agricultural production. Biodiversity 9: 86-89.

Thompson FC, Rotheray GE \& Zumbado MA (2010) Syrphidae. Manual of Central American Diptera (ed. by BV Brown, A Borkent, JM Cumming, DM Wood, NE Woodley \& MA Zumbado), pp. 763-792. NRC Research Press, Ottawa, Canada.

Valdés B, Díez MJ \& Fernández I (1987) Atlas Polínico de Andalucía Occidental. Instituto de Desarrollo Regional de la Universidad de Sevilla, Sevilla, Spain.

Wiering D (1964) The use of insects for pollinating Brassica crops in small isolation cages.

Euphytica 13: 24-28.

Wilkinson JJ (1901) The Pharynx of the Eristalis Larva. Richard Clay and Sons, London, UK.

Willmer P (2011) Pollination and Floral Ecology. Princeton University Press, New Jersey, NJ, USA.

Wipfler B, Schneeberg K, Löffler A, Hünefeld F, Meier R \& Beutel RG (2013) The skeletomuscular system of the larva of Drosophila melanogaster (Drosophilidae, Diptera). A contribution to the morphology of a model organism. Arthropod Structure \& Development 42: 47-68.

\section{Figure captions}

Figure 1 Scanning electron microscopy (SEM) images of Eristalinus aeneus larvae, ventral view 
of pseudocephalon, prothorax and mesothorax. (A) Third instar, (B) second instar, (C) first instar, and (D) third instar, detail of preoral cavity. Abbreviations: $\mathrm{Am}=$ antennomaxillary organs, $\mathrm{Dl}=$ dorsal lip, $\mathrm{Ds}=$ dorsal sensilla, $\mathrm{Ll}=$ lateral lip, $\mathrm{Mlj}=$ mandibular lobe joining, $\mathrm{Mp}=$ mesothoracic proleg, $\mathrm{Vl}=$ ventral lip, and Vs = ventra sensilla. Scale bars: (A, B) $1 \mathrm{~mm},(\mathrm{C}) 100 \mu \mathrm{m}$, and (D) $300 \mu \mathrm{m}$.

Figure 2 Diagrams of the Eristalinus aeneus head skeleton. (A) Third instar, lateral view, (B) third instar, ventral view, (C) first instar, lateral view, and (D) first instar, ventral view. Abbreviations: $\mathrm{Bs}=$ basal sclerite, $\mathrm{C}=$ cibarium, $\mathrm{Db}=$ dorsal bridge, $\mathrm{Dc}=$ dorsal cornu, $\mathrm{Ep}=$ epipharyngeal plate, $\mathrm{Lb}=$ labial bridge, $\mathrm{Lbr}=$ labrum, $\mathrm{Lp}=$ labial plate, $\mathrm{Lr}=$ labial rods, $\mathrm{Ls}=$ labial sclerite, $\mathrm{M}=$ mandibles, $\mathrm{Ma}=$ mandibular apodeme, $\mathrm{Ml}=$ mandibular lobes, $\mathrm{Od}=$ optical depression, $\mathrm{Va}=$ ventral $\mathrm{arm}, \mathrm{Vc}=$ ventral cornu, and $\mathrm{Vp}=$ vertical plate. Scale bars: $(\mathrm{A}, \mathrm{B}) 500$ $\mu \mathrm{m}$, (B) $600 \mu \mathrm{m}$, and (C, D) $200 \mu \mathrm{m}$.

Figure 3 Scanning electron microscopy (SEM) images of Eristalinus aeneus filtering structures. (A) Inner part of mandibular lobe, (B) detail of ridges and bristles of the mandibular lobe, and (C) cibarial chamber. Abbreviations: $\mathrm{Brt}=$ bristles, $\mathrm{M}=$ mandibles, $\mathrm{F}=$ filaments, and $\mathrm{Rg}=$ ridges. Scale bars: (A) $100 \mu \mathrm{m}$, (B) $25 \mu \mathrm{m}$, and (C) $200 \mu \mathrm{m}$.

Figure 4 Frequency (\%) of particle intake of Eristalinus aeneus first (L1), second (L2), and third (L3) larval instars. Particles were 6-100 $\mu \mathrm{m}$ in size, and each instar was offered all 10 particles (pollen grains and fungal spores) individually $(\mathrm{n}=15)$. Full species names of the organisms from which the particles were obtained are listed in Table 1.

Figure 5 Scanning electron microscopy (SEM) images of Eristalis tenax larvae, ventral view of pseudocephalon, prothorax and mesothorax. (A) Third instar, (B) second instar, (C) first instar, and (D) third instar, detail of preoral cavity. Abbreviations: Am = antennomaxillary organs, $\mathrm{Dl}=$ dorsal lip, $\mathrm{Ds}=$ dorsal sensilla, $\mathrm{Ll}=$ lateral lip, $\mathrm{Mlj}=$ mandibular lobe joining, $\mathrm{Mp}=$ mesothoracic proleg, Vl = ventral lip, Vs = ventra sensilla. Scale bars: (A) 1mm, (C) $100 \mu \mathrm{m}$, and (B, D) 300 $\mu \mathrm{m}$.

Figure 6 Diagrams of the Eristalis tenax head skeleton. (A) Third instar, lateral view, (B) third 
instar, ventral view, (C) first instar, lateral view, and (D) first instar, ventral view. Abbreviations: $\mathrm{Bs}=$ basal sclerite, $\mathrm{C}=$ cibarium, $\mathrm{Dc}=$ dorsal cornu, $\mathrm{Db}=$ dorsal bridge, $\mathrm{Ep}=$ epipharyngeal plate, $\mathrm{Lb}=$ labial bridge, $\mathrm{Lbr}=$ labrum, $\mathrm{Lp}=$ labial plate, $\mathrm{Lr}=$ labial rods, $\mathrm{Ls}=$ labial sclerite, $\mathrm{M}=$ mandibles, $\mathrm{Ma}=$ mandibular apodeme, $\mathrm{Ml}=$ mandibular lobes, $\mathrm{Od}=$ optical depression, $\mathrm{Va}=$ ventral arm, $\mathrm{Vc}=$ ventral cornu, and $\mathrm{Vp}=$ vertical plate. Scale bars: (A, B) $500 \mu \mathrm{m}$ and (C, D) 200 $\mu \mathrm{m}$.

Figure 7 Scanning electron microscopy (SEM) images of Eristalis tenax filtering structures. (A) Inner part of mandibular lobe, (B) detail of detached ridges inside the mandibular lobe, and (C) head skeleton of the third instar larva, dorsal view. Abbreviations: $\mathrm{C}=$ cibarium, $\mathrm{Drg}=$ ridges, and $\mathrm{Ml}=$ mandibular lobes. Scale bars: (A) $200 \mu \mathrm{m}$, (B) $50 \mu \mathrm{m}$, and (C) $500 \mu \mathrm{m}$.

Figure 8 Confocal laser scanning microscopy (CLSM) images of Eristalis tenax filtering structures. (A) Mandibular lobes of the second instar larva, (B) mandibular lobes of the first instar larva, and (C) cibarial chamber of the first instar larva. Scale bars: (A) $100 \mu \mathrm{m}$, (B) $50 \mu \mathrm{m}$, and (C) $10 \mu \mathrm{m}$.

Figure 9 Frequency (\%) of particle intake of Eristalis tenax first (L1), second (L2), and third (L3) larval instars. Particles were 6-100 $\mu \mathrm{m}$ in size, and each instar was offered all 10 particles (pollen grains and fungal spores) individually $(n=15)$. Full species names of the organisms from which the particles were obtained are listed in Table 1.

Figure 10 Scanning electron microscopy (SEM) images of Eristalis tenax third instar larva cibarial chamber, bearing (A) microorganisms on the ridges and (B) filaments. Scale bars: $10 \mu \mathrm{m}$.

\section{Supporting Information}

Additional Supporting Information may be found in the online version of this article.

Video S1 This video displays a sequence of images taken with Confocal laser scanning microscopy (CLSM). The images are of the thorax region of the first instar larva (L1) of Eristalis tenax. Images are sequenced in Z-axis, showing first the dorsal surface of the larvae, then the 
internal muscles and the head skeleton and afterwards the ventral surface.

This article is protected by copyright. All rights reserved 
Table 1 Plant and fungi species from which the pollen grains and fungal spores were extracted and their size. Particles were selected based on bibliographic research, and their size was verified by manual measurement using a micrometric eyepiece in the microscope

\begin{tabular}{ll}
\hline Species & Diameter $(\boldsymbol{\mu m})$ \\
\hline Lavatera cretica L. & 100 \\
Pelargonium zonale (L.) L'Hér. & 80 \\
Convolvulus althaeoides L. & $65-70$ \\
Pinus halepensis Mill. & $50 \times 80^{1}$ \\
Acacia dealbata Link. & 50 \\
Sonchus tenerrimus L. & 40 \\
Quercus ilex L. & 25 \\
Leocarpus fragilis (Dicks.) Rostaf. & 12 \\
Agrocybe aegerita (V.Brig.) Sing. & $12 \times 6^{1}$ \\
Inocybe spp. (Fr.) Fr. & $12 \times 7^{1}$
\end{tabular}

${ }^{1}$ Particles not rounded in shape. 
Table 2 Head skeleton measurements (mean \pm standard error) of the third (L3), second (L2) and first (L1) instars of Eristalinus aeneus and Eristalis tenax. Measurements were obtained from scanning electron microscopy (SEM) images

\begin{tabular}{|c|c|c|c|c|c|c|c|}
\hline Instar & Measurements & Eristalinus ae & & & Eristalis tenax & & \\
\hline & & Mean \pm SE & Range & $\mathrm{n}$ & Mean $\pm \mathrm{SE}$ & Range & $\mathrm{n}$ \\
\hline Third (L3) & Total width (mm) & $0.77 \pm 0.0064$ & $0.7-0.8$ & 20 & $0.79 \pm 0.0065$ & $0.7-0.9$ & 20 \\
\hline & Cibarial chamber & $0.69 \pm 0.0054$ & $0.7-0.7$ & 20 & $0.52 \pm 0.0041$ & $0.5-0.6$ & 20 \\
\hline & width (mm) & & & & & & \\
\hline & Max. height (mm) & $0.92 \pm 0.014$ & $0.8-1.8$ & 20 & $1.12 \pm 0.023$ & $1.0-1.3$ & 20 \\
\hline & Max. length $(\mathrm{mm})$ & $2.31 \pm 0.023$ & $2.1-2.5$ & 20 & $2.33 \pm 0.015$ & $2.2-2.4$ & 20 \\
\hline Second (L2) & Max. height $(\mathrm{mm})$ & $0.39 \pm 0.088$ & $0.3-0.5$ & 20 & $0.51 \pm 0.0087$ & $0.4-0.6$ & 20 \\
\hline & Max. length (mm) & $1.07 \pm 0.24$ & $1.0-1.2$ & 20 & $1.16 \pm 0.0083$ & $1.1-1.2$ & 20 \\
\hline First (L1) & Max. height (mm) & $0.13 \pm 0.0043$ & $0.1-0.2$ & 20 & $0.16 \pm 0.0076$ & $0.1-0.3$ & 20 \\
\hline & Max. length (mm) & $0.49 \pm 0.0089$ & $0.4-0.6$ & 20 & $0.46 \pm 0.0065$ & $0.4-0.5$ & 20 \\
\hline
\end{tabular}


Table 3 Cibarial measurements (mean \pm standard error) from third instar larvae (L3) of Eristalinus aeneus and Eristalis tenax. Measurements were obtained from scanning electron microscopy (SEM) images

Measurements Eristalinus aeneus Eristalis tenax

\begin{tabular}{|c|c|c|c|c|c|c|}
\hline & & & & & & \\
\hline & Mean \pm SE & Range & $\mathrm{n}$ & Mean \pm SE & Range & $\mathrm{n}$ \\
\hline $\begin{array}{l}\text { Distance between ridges } \\
(\mu \mathrm{m})\end{array}$ & $74.39 \pm 1.30$ & $62.3-88.4$ & 25 & $51.06 \pm 1.16$ & $40.0-62.0$ & 25 \\
\hline No. filaments $\mathrm{mm}^{-1}$ & $1250.32 \pm 41.07$ & $1004.4-1620.2$ & 20 & $1396.83 \pm 49.94$ & 1102.1-1908.4 & 21 \\
\hline Length of filaments $(\mu \mathrm{m})$ & $45.05 \pm 2.55$ & $36.6-59.5$ & 20 & $38.34 \pm 3.44$ & $27.8-51.4$ & 19 \\
\hline Width of filaments $(\mu \mathrm{m})$ & $1.93 \pm 0.11$ & $0.7-2.6$ & 25 & $2.58 \pm 0.06$ & $1.7-3.1$ & 25 \\
\hline
\end{tabular}


Table 4 Mandibular lobe inner surface measurements (mean \pm standard error) from third instar larvae (L3) of Eristalinus aeneus and Eristalis tenax

\begin{tabular}{lllllllll}
\hline Measurements & \multicolumn{2}{l}{ Eristalinus aeneus } & & & Eristalis tenax & & \\
\cline { 2 - 3 } & Mean $\pm \mathrm{SE}$ & Range & $\mathrm{n}$ & & Mean $\pm \mathrm{SE}$ & & Range & $\mathrm{n}$ \\
\hline No. ridges & $10.20 \pm 0.29$ & $9.0-13.0$ & 20 & & $19.30 \pm 0.48$ & $17.0-24.0$ & 20 \\
Distance between ridges $(\mu \mathrm{m})$ & $33.71 \pm 1.61$ & $20.5-45.7$ & 21 & & $13.73 \pm 0.87$ & $8.1-21.7$ & 23 \\
No. bristles $10 \mu \mathrm{m}^{-1}$ & $1.57 \pm 0.11$ & $1.0-2.3$ & 20 & & $2.54 \pm 0.06$ & $2.0-3.1$ & 25 \\
Distance between bristles $(\mu \mathrm{m})$ & $5.85 \pm 0.28$ & $3.5-7.5$ & 16 & & $2.84 \pm 0.12$ & $1.7-4.3$ & 25 \\
Length of bristles $(\mu \mathrm{m})$ & $12.78 \pm 0.84$ & $6.5-21.3$ & 25 & & $6.92 \pm 0.18$ & $5.6-8.9$ & 23 \\
Width of bristles $(\mu \mathrm{m})$ & - & - & - & & $1.62 \pm 0.04$ & & $1.0-2.2$ & 18 \\
\hline
\end{tabular}



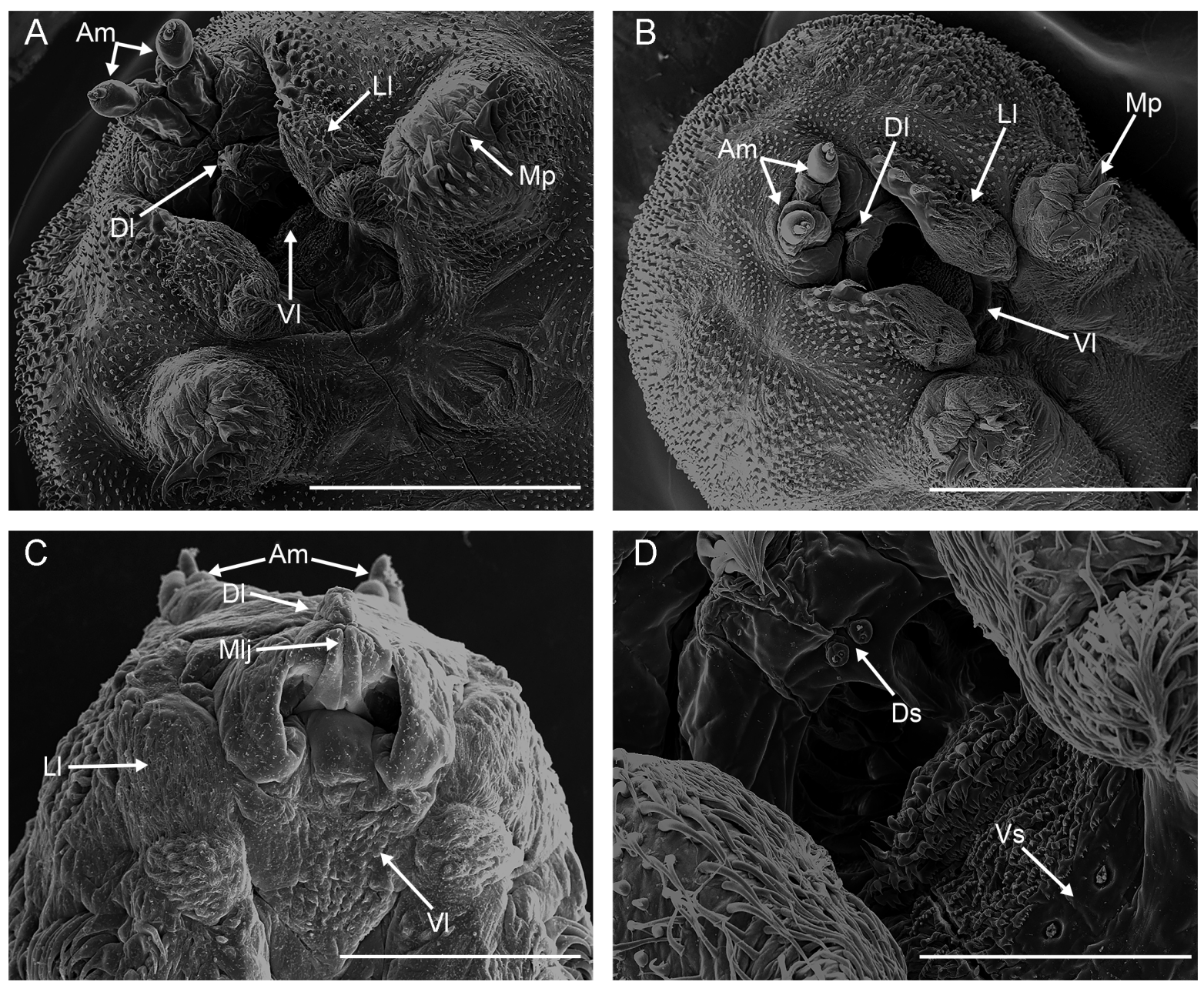

eea_12974_f1.tif

This article is protected by copyright. All rights reserved 
A

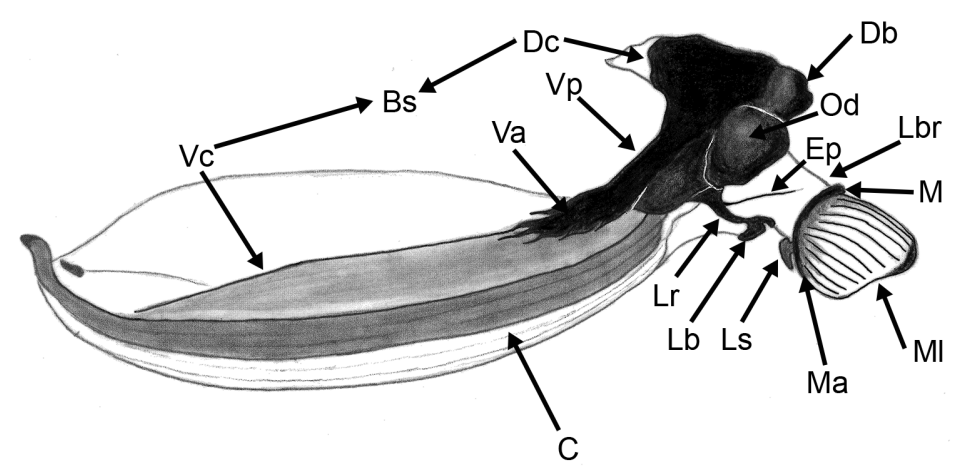

C

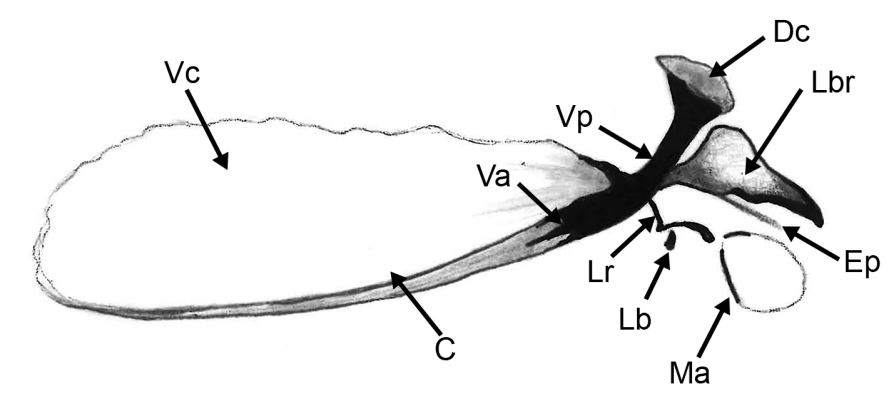

eea_12974_f2.tif
B
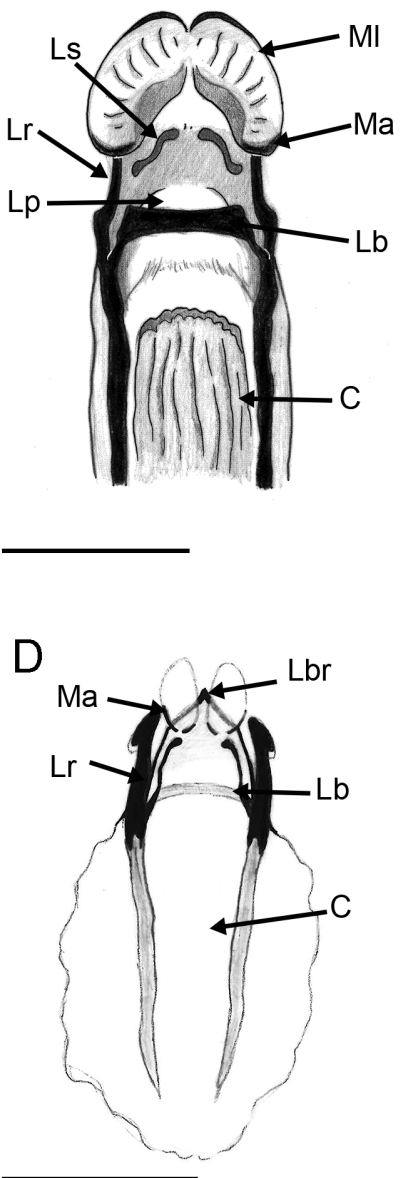

This article is protected by copyright. All rights reserved 

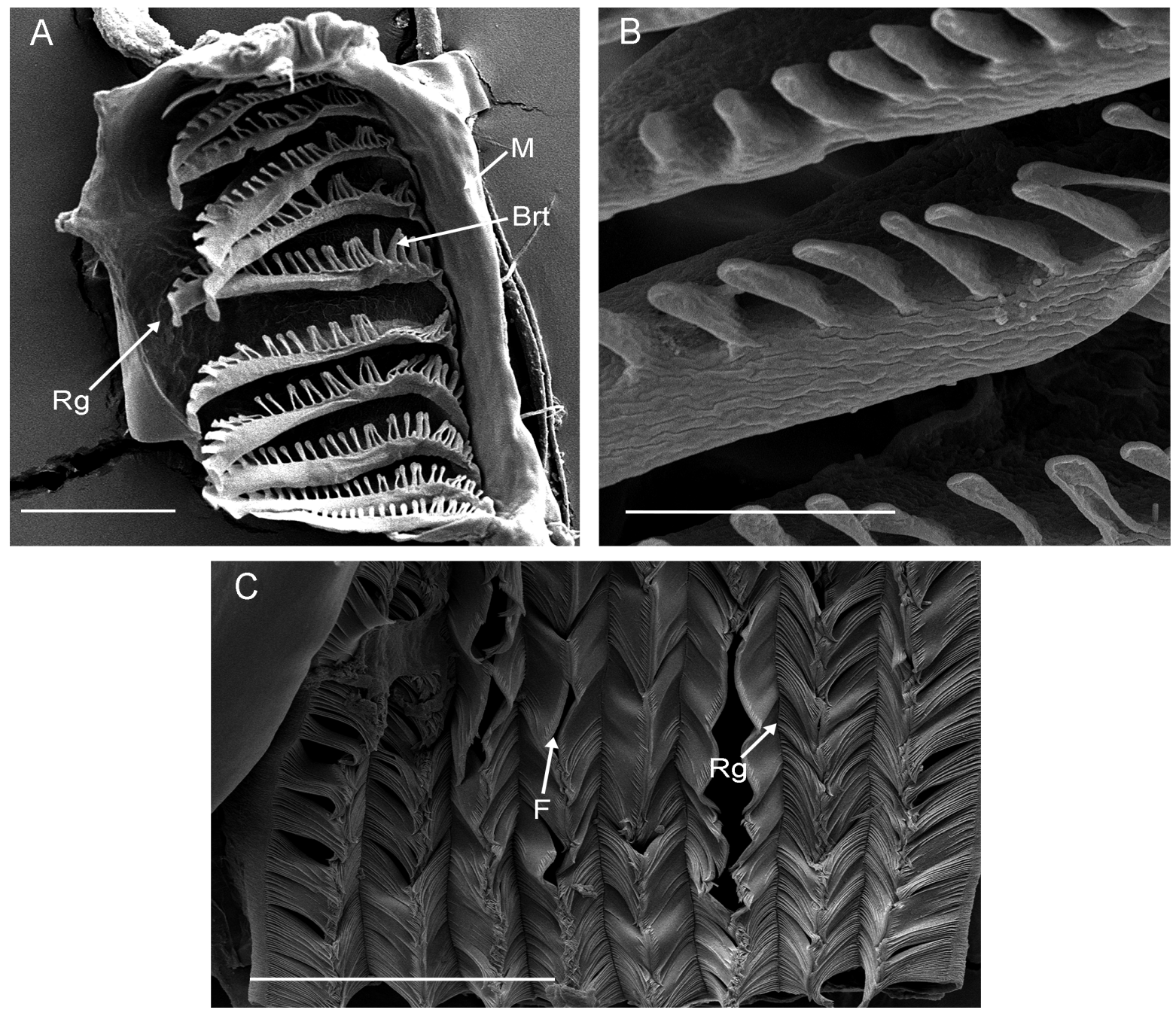

eea_12974_f3.tif

This article is protected by copyright. All rights reserved 


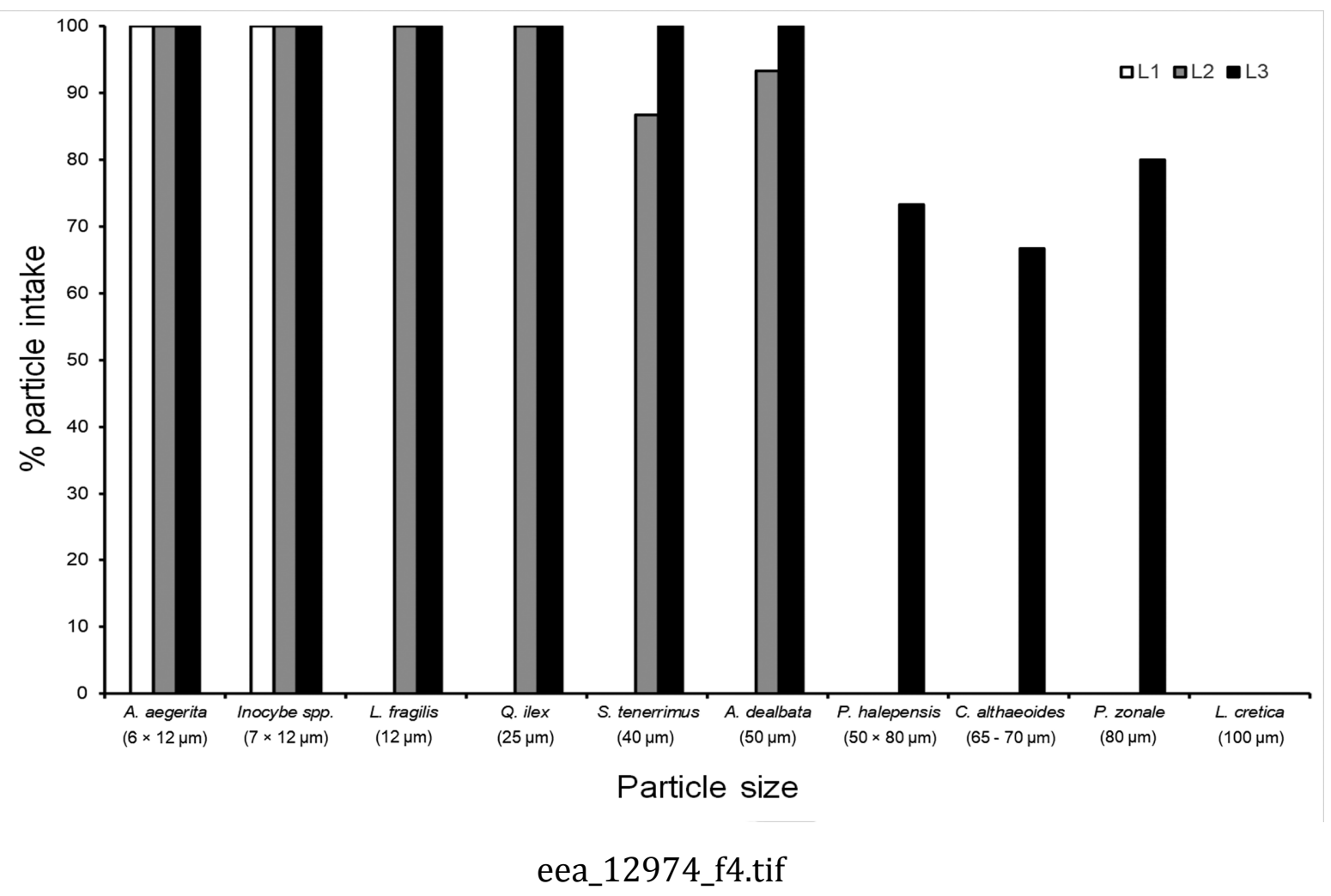

This article is protected by copyright. All rights reserved 

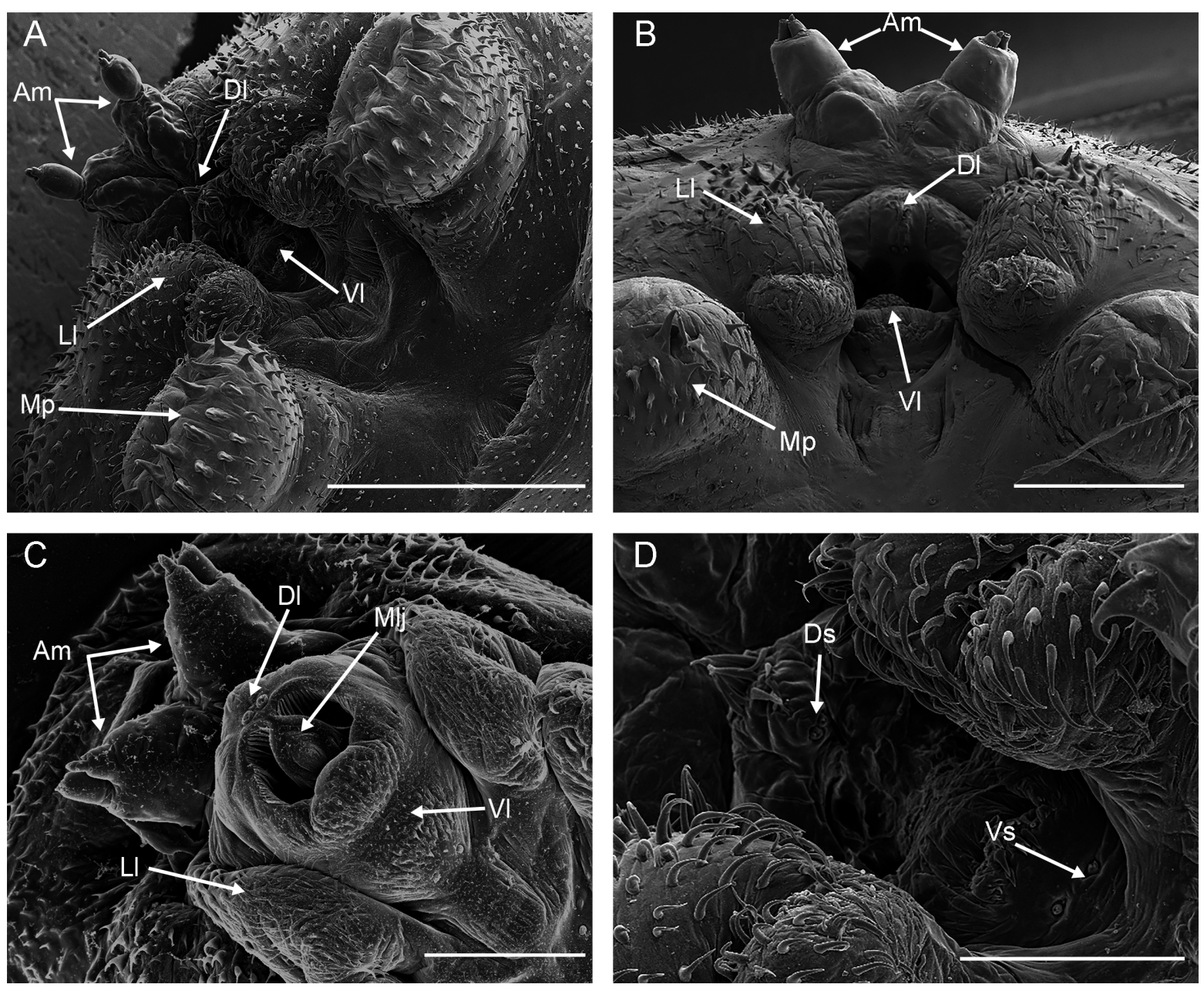

eea_12974_f5.tif

This article is protected by copyright. All rights reserved 
A

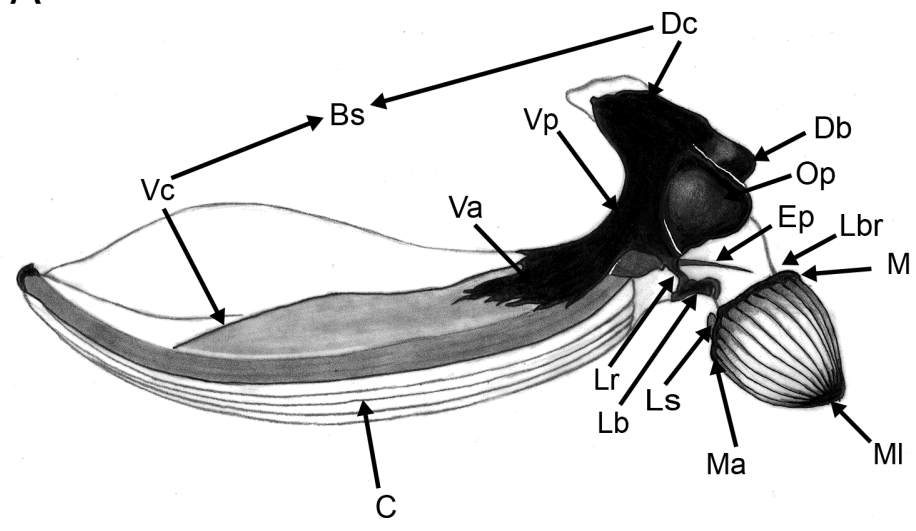

C

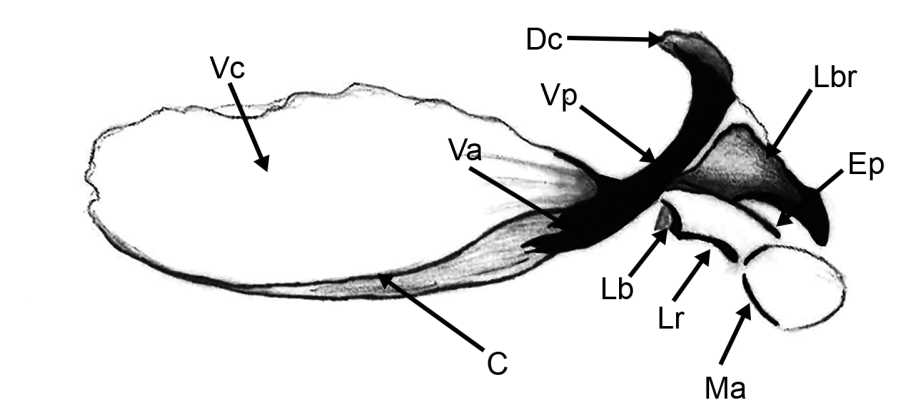

B
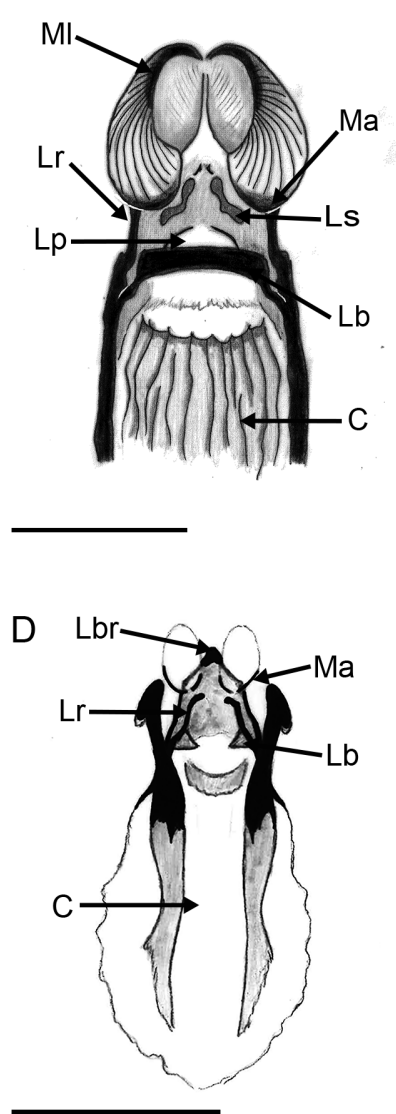

eea_12974_f6.tif 

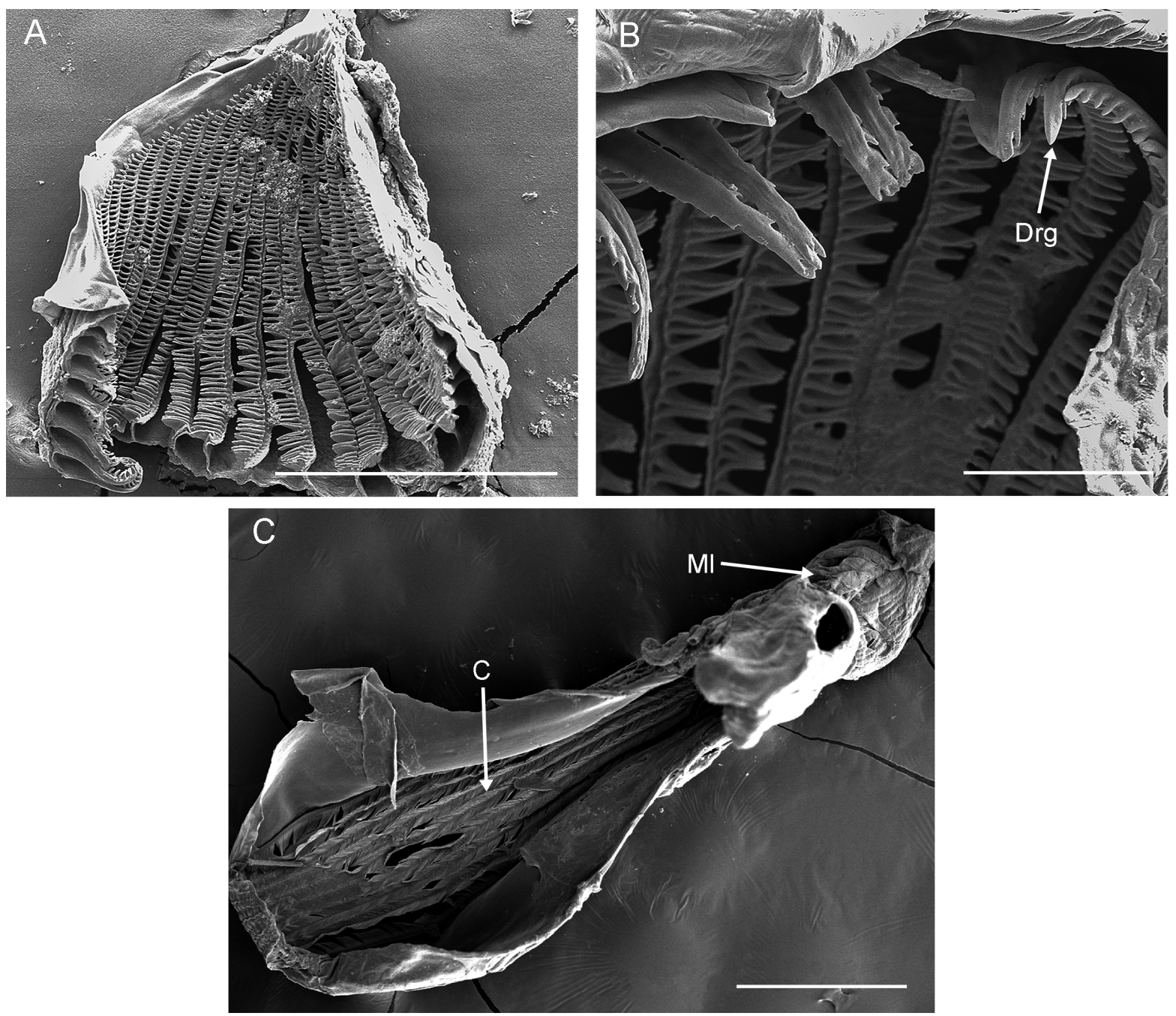

eea_12974_f7.tif

This article is protected by copyright. All rights reserved 

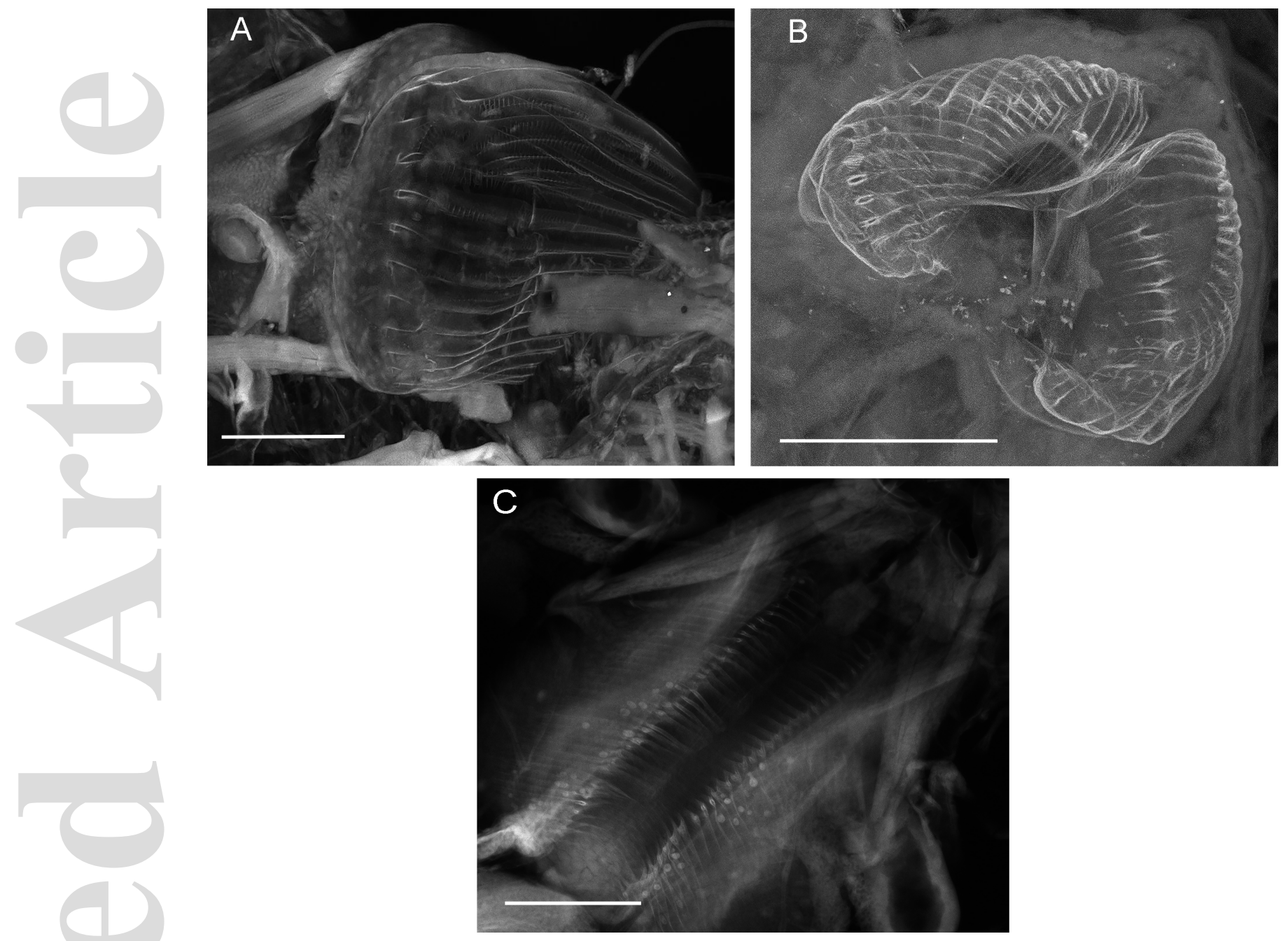

eea_12974_f8.tif 


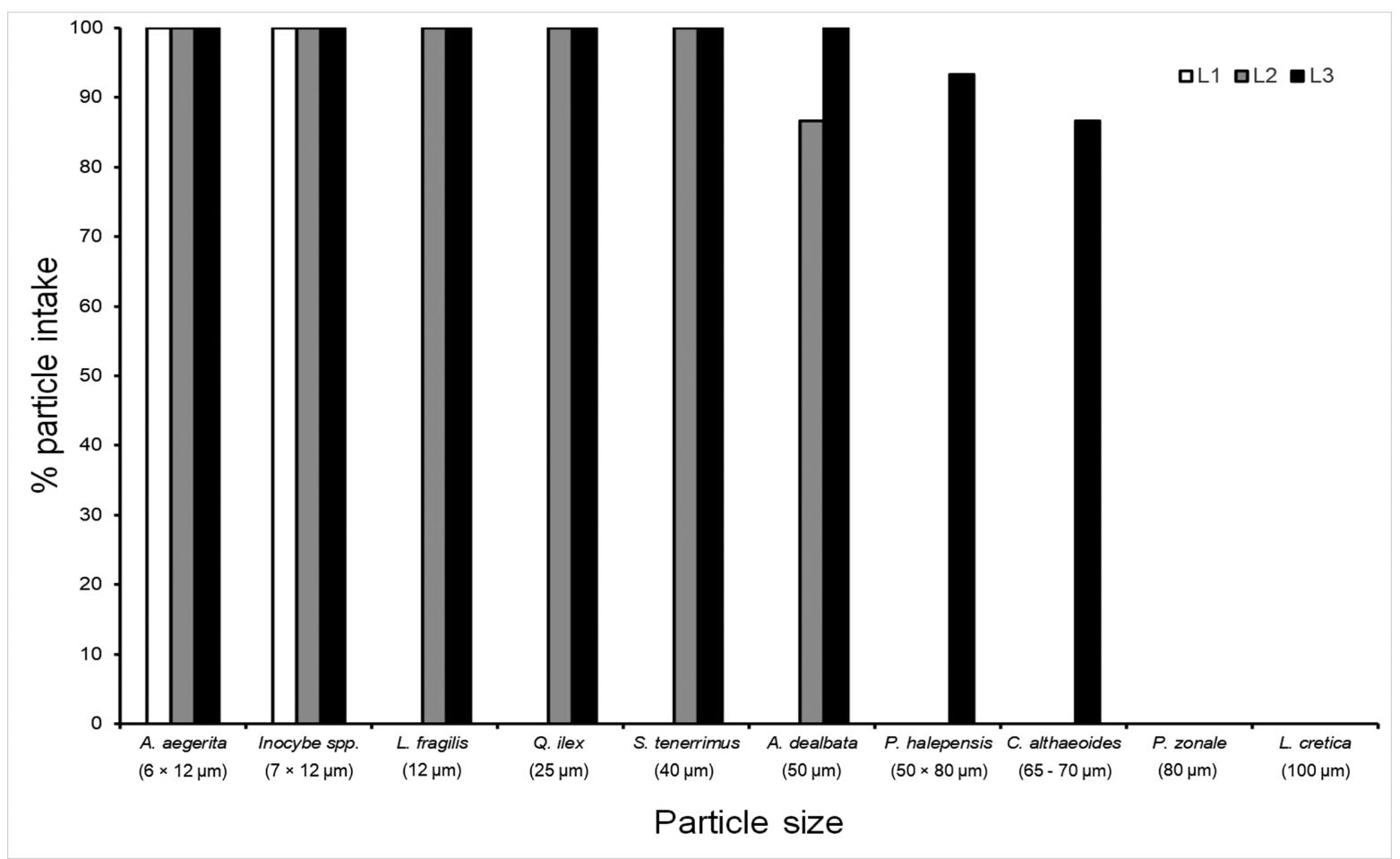

eea_12974_f9.tif 

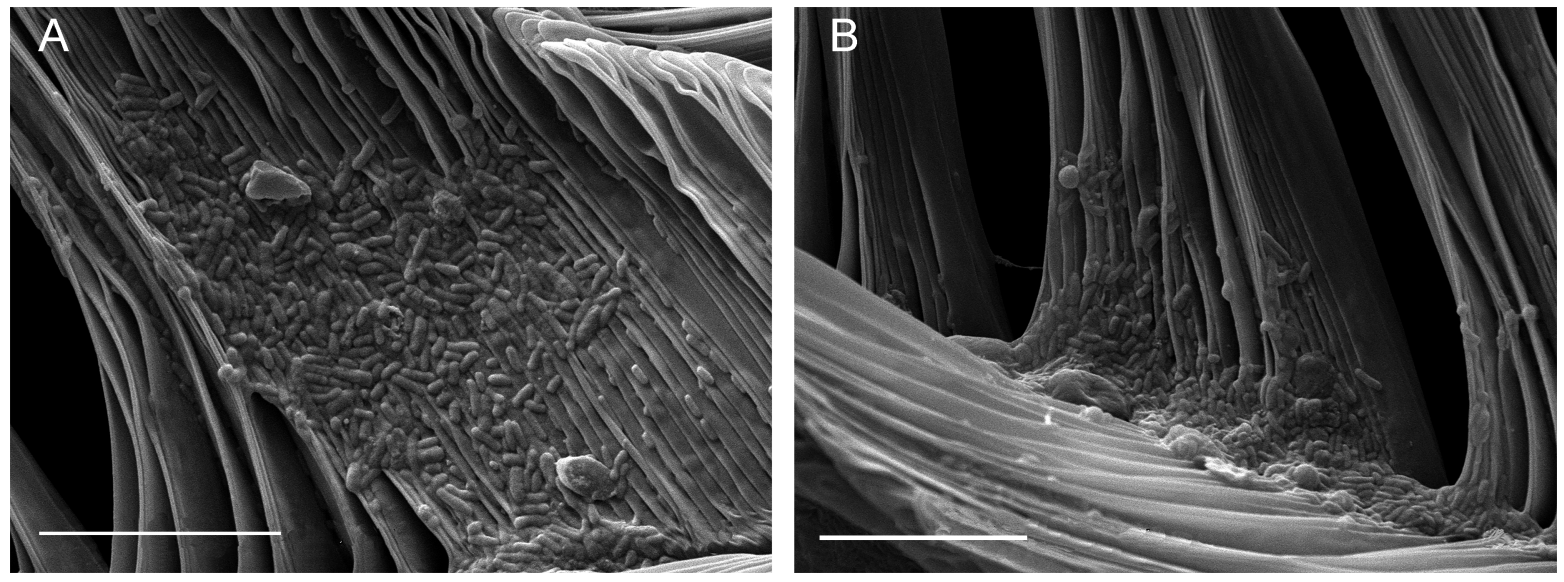

eea_12974_f10.tif 